\title{
Dietas de diferentes densidades energéticas mantendo constante a relação energia metabolizável:nutrientes para codornas japonesas em postura
}

\author{
Guilherme de Souza Moura ${ }^{1}$, Sergio Luiz de Toledo Barreto², Juarez Lopes Donzele ${ }^{2}$, Lúcia \\ Reiko Hosoda ${ }^{3}$, Graciane de Miranda Pena ${ }^{3}$, Marjorie Sartorelli Angelini ${ }^{3}$ \\ ${ }_{1}$ Programa de Pós-graduação em Zootecnia - Universidade Federal de Viçosa - MG. \\ 2 Departamento de Zootecnia, Universidade Federal de Viçosa - MG. \\ ${ }^{3}$ Curso de Graduação em Zootecnia, Universidade Federal de Viçosa - MG.
}

RESUMO - Objetivou-se avaliar os efeitos da redução da densidade energética das dietas no desempenho de codornas japonesas em produção mantendo-se constante a relação energia metabolizável (EM):nutrientes. Foram utilizadas 400 codornas japonesas com peso inicial de $155 \pm 15,5$ g e 76 a 160 dias de idade, distribuídas em delineamento inteiramente casualizado, com cinco tratamentos (densidades energéticas: 2.900, 2.800, 2.700, 2.600 e $2.500 \mathrm{kcal}$ de EM/kg), oito repetições e dez aves por unidade experimental. Observou-se diferença no consumo de ração e na conversão alimentar por massa e por dúzia de ovos relacionada ao nível energético da dieta. Entretanto, as dietas não influenciaram os consumos de EM, proteína bruta, lisina, metionina+cistina e treonina, a produção de ovos, a produção de ovos comercializáveis, o peso e a massa de ovo, a eficiência energética por massa de ovo e por dúzia de ovos, o ganho de peso e a viabilidade das aves. Para codornas japonesas em postura, dietas contendo 2.900 e $2.800 \mathrm{kcal}$ de EM/kg proporcionam melhor conversão alimentar por massa e por dúzia de ovos, respectivamente, quando se mantém a relação EM:nutrientes.

Palavras-chave: Coturnix coturnix japonica, desempenho de codornas, nutrição de codornas, redução energética

\section{Diets of different energetic densities, keeping constant the metabolizable energy:nutrients ratio, for laying Japanese quails}

\begin{abstract}
The aim of this experiment was to evaluate the effects of energetic density reduction in diets in the performance of Japanese quail, keeping constant the metabolizable energy (ME) to nutrients ratio. A total of 400 Japanese quails with $155 \mathrm{~g} \pm 5.5 \mathrm{~g}$ and 76 to 160 days old were distributes to a complete randomized experimental design with five energetic density, eight replicates and ten birds per experimental unit. Five energetic density in the diets was evaluated (2,900, 2,800, 2,700, 2,600, and 2,500 kcal ME/kg of diet) keeping constant the metabolizable energy to nutrients ratio. The birds were fullfed during all experimental period. It was observed difference for feed intake, feed conversion per egg mass and feed conversion per egg dozen related to energy level in the diet. However, the diets did not influence the intakes of energy, crude protein, lysine, methionine+cystine, threonine, egg production, commercial egg production, egg mass, energy efficiency per egg mass, energy efficiency per egg dozen, weight gain and quail viability. For Japanese quail in posture, diets with 2,900 and 2,800 kcal ME/kg provided better feed conversion per egg mass and feed conversion per egg dozen, respectively, when the metabolizable to nutrients ratio is kept.
\end{abstract}

Key Words: Coturnix coturnix japonica, energetic reduction, quail nutrition, quail performnance

\section{Introdução}

A coturnicultura é um ramo da agropecuária que tem despertado interesse de produtores e pesquisadores por suas vantagens produtivas. Entre as aves, a codorna é uma das mais precoces e produtivas, pois inicia sua postura por volta do $40^{\circ}$ dia de idade e produz, em média, 300 ovos no seu primeiro ano de vida.

O balanceamento das dietas para melhorar o desempenho de codornas e a qualidade de seus ovos ainda é um desafio.
Por haver poucos trabalhos sobre exigências nutricionais destas aves no Brasil, têm-se utilizado tabelas de exigências nutricionais preconizadas pelo NRC (1994) e INRA (1998), que certamente não são apropriadas às aves criadas nas condições brasileiras.

No sistema de criação de codornas com alimentação , o consumo é regulado pela densidade energética da ração e pela exigência nutricional, portanto, é imprescindível o conhecimento acurado de suas relações. Quando ocorre aumento no nível energético da ração, o consumo voluntário 
diminui (Silva et al., 2003), reduzindo a produção de ovos (Murakami \& Furlan, 2002). Portanto, as exigências nutricionais das aves devem ser expressas em relação ao seu conteúdo energético, principalmente as exigências protéicas, considerando todo o perfil aminoacídico (Chwalibog \& Baldwin, 1995; Murakami, 2002).

Trabalhando com rações contendo 16, 18, 20 ou 22\% de proteína bruta e 2.500, 2.700, 2.900 e 3.100 kcal de energia metabolizável (EM)/kg, Murakami et al. (1993) verificaram que os melhores níveis para codornas japonesas na fase de postura são de $18 \%$ de PB e de $2.700 \mathrm{kcal}$ de EM/kg. Além disso, observaram que o nível de $19,66 \%$ de proteína promoveu a melhor conversão alimentar por massa de ovos. No entanto, Pinto et al. (2002) verificaram que os níveis de $2.850 \mathrm{kcal}$ de EM e 22,4\% de PB foram os mais adequados para máximo desempenho das aves.

Os dados encontrados na literatura indicam que a relação EM:PB para melhor desempenho de codornas em postura são de 125 a 150:1, como base para cálculo de EM, PB e outros nutrientes. Portanto, são necessários novos estudos para obtenção de dados mais consistentes para melhor ajuste na formulação de rações.

Neste trabalho, objetivou-se estudar o efeito da redução da densidade energética de dietas, mantendo constante a relação EM:nutrientes, no desempenho de codornas japonesa em postura.

\section{Material e Métodos}

O experimento foi realizado no setor de Avicultura do Departamento de Zootecnia do Centro de Ciências Agrárias da Universidade Federal de Viçosa, Minas Gerais, no período de agosto de 2005 a fevereiro de 2006. Foram utilizadas 400 codornas (Coturnix coturnix japonica) provenientes da Granja Fujikura (Suzano - São Paulo) com 76 dias de idade e peso inicial de $155 \pm 15,5$ g até os 160 dias de idade.

O delineamento experimental foi o inteiramente casualizado, com cinco tratamentos, dez repetições e oito aves por unidade experimental. As aves foram alojadas em gaiolas de arame galvanizado, com as dimensões de $100 \times$ $23 \times 20 \mathrm{~cm}$ (comprimento $\times$ largura $\times$ altura), dispostas em três andares montados em esquema de escada. Cada gaiola foi subdividida em duas repartições iguais de $50 \mathrm{~cm}$, sendo alojadas dez aves em cada repartição, fornecendo uma área de $115 \mathrm{~cm}^{2}$ /ave. O comedouro e o bebedouro utilizados foram do tipo calha, em chapa metálica galvanizada, ambos percorrendo toda a extensão das gaiolas: o comedouro na parte frontal e o bebedouro na parte posterior da gaiola.
Sobre o piso de cimento, abaixo das gaiolas, foi colocada uma camada de maravalha para absorver o excesso de umidade das excretas. O uso de cal sobre as excretas foi necessário durante todo período experimental para promover a redução da umidade e da concentração de amônia no interior do galpão.

Na formulação das dietas das aves, foram consideradas as exigências nutricionais preconizadas pelo NRC (1994), exceto as de lisina, metionina + cistina (met + cis), treonina e cálcio. As exigências de lisina e de met + cis foram baseadas nas recomendações de Pinto et al. (2003) e as de cálcio e de treonina, nas recomendações de Barreto et al. (2007) e Umigi et al. (2007), respectivamente, dando continuidade aos trabalhos de exigência já desenvolvidos no Departamento de Zootecnia da Universidade Federal de Viçosa para a espécie Coturnix coturnix japonica.

Para atender o objetivo proposto, foram formuladas cinco dietas à base de milho, farelo de soja e farelo de trigo (Tabela 1), todas com mesma relação entre energia metabolizável e nutrientes. A dieta e a água foram fornecidas à vontade durante todo período experimental. O manejo diário consistiu da coleta e contagem dos ovos (foram computados diariamente o número de ovos quebrados, trincados, com casca mole e sem casca), do fornecimento da dieta, da limpeza dos bebedouros e dos aparadores de ovos e da leitura das temperaturas e da umidade relativa do ar.

As temperaturas $\left({ }^{\circ} \mathrm{C}\right)$ e a umidade relativa do ar do aviário foram monitoradas uma vez ao dia, às $16 \mathrm{~h}$, por meio de termômetros de máxima e de mínima e de bulbo seco e úmido posicionados em um ponto central entre as fileiras de gaiolas, à altura das aves.

O programa de iluminação foi imposto quando as aves atingiram 40 dias de idade e consistiu do fornecimento inicial de 14 horas de luz por dia e de aumentos semanais de 30 minutos de luz até atingir 17 horas de luz por dia, mantido até o término do período experimental. O fornecimento de luz foi controlado por um relógio automático (timer) que permitia acender e apagar as luzes automaticamente durante a noite, conforme procedimento adotado em granjas comerciais.

Durante o experimento, avaliaram-se os consumos de ração (g/ave/dia), energia metabolizável (kcal/ave/dia), proteína bruta (g/ave/dia), lisina (mg/ave/dia), metionina + cistina (mg/ave/dia) e treonina (mg/ave/dia), as produções de ovos (\%) e de ovos comercializáveis (\%), o peso médio dos ovos (g), a massa de ovos (g/ave/dia), a conversão alimentar por massa $(\mathrm{kg} / \mathrm{kg})$ e por dúzia de ovos (kg/dúzia), a eficiência energética por massa (kcal/kg) e por dúzia de ovos (kcal/ dúzia), o ganho de peso (g) e a viabilidade das aves (\%). 
Tabela 1 - Composição das dietas experimentais para codornas japonesas na fase de postura (na matéria natural)

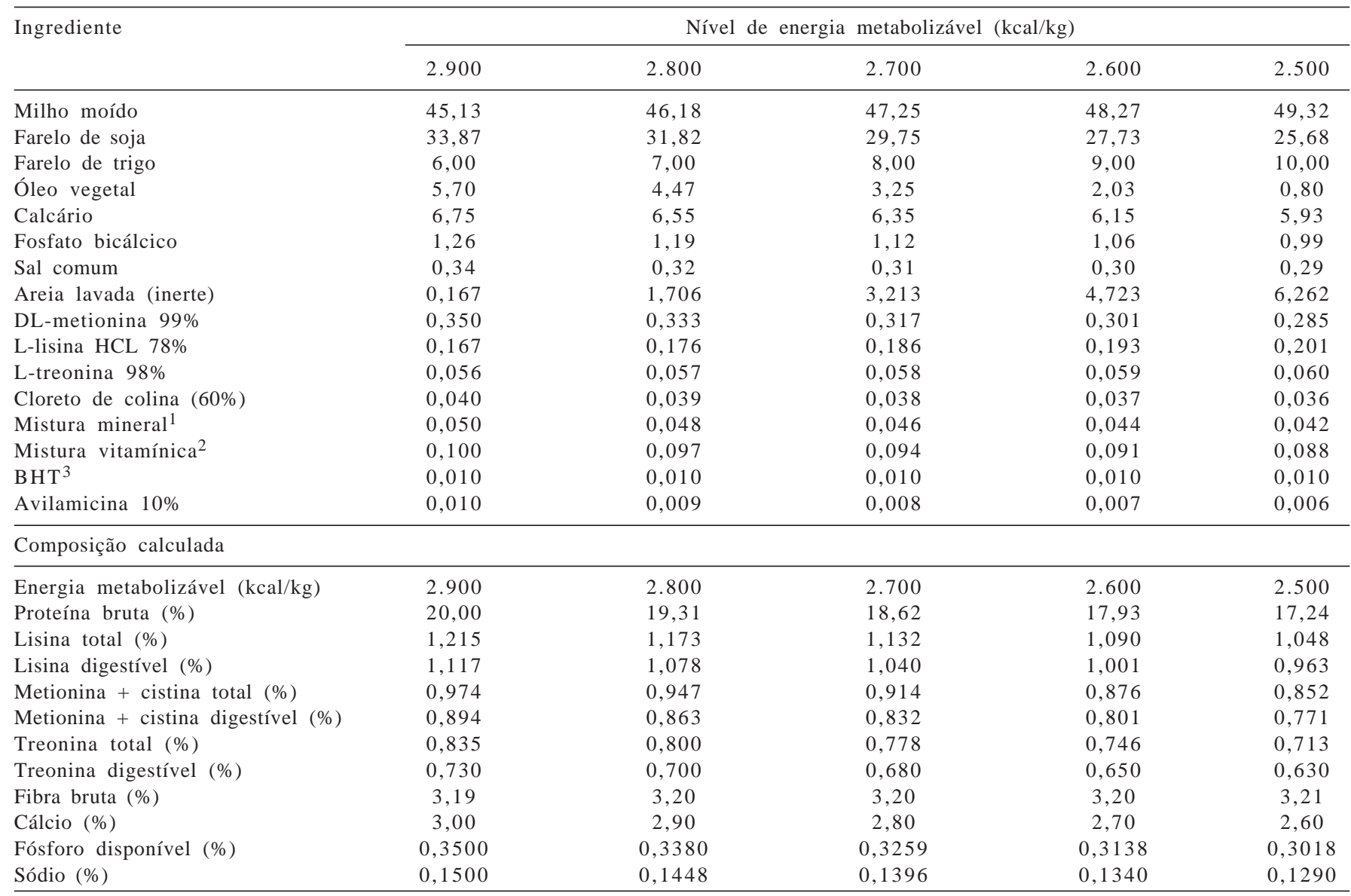

${ }^{1}$ Composição/kg: vit. A - 12.000 .000 UI; vit $\mathrm{D}_{3}-3.600 .000 \mathrm{UI}$; vit. E - $3.500 \mathrm{UI}$; vit $\mathrm{B}_{1}-2.500 \mathrm{mg}$; vit $\mathrm{B}_{2}$ - $8.000 \mathrm{mg}$; vit. $\mathrm{B}_{6}$ - $5.000 \mathrm{mg}$; ácido pantotênico 12.000 mg; biotina - 200 mg; vit. K - 3.000 mg; ácido fólico - 1.500 mg; ácido nicotínico - 40.000 mg; vit. B 12 - 20.000 mg; Se - 150 mg; veículo q.s.p. $-1.000 \mathrm{~g}$.

${ }^{2}$ Composição/kg: Mn - 160 g; Fe - 100g; Zn -100 g; Cu - 20 g; Co - 2 g; I - 2 g; veículo q.s.p. - 1.000 g

3 Butil-hidróxi-tolueno (antioxidante).

Durante o período experimental, as médias das temperaturas $\left({ }^{\circ} \mathrm{C}\right)$, mínima e máxima, e a umidade relativa do ar (\%) medidas no interior do aviário foram de 20,0; 28,8 e 88,8; respectivamente.

Os resultados obtidos foram submetidos à análise de variância e, para qualificar as variáveis, adotou-se o teste Student Newman Keuls (SNK) para comparação entre médias. Todas as análises foram feitas utilizando-se o programa SAEG - Sistemas para Análises Estatísticas e Genéticas UFV(2004).

\section{Resultados e Discussão}

As dietas influenciaram o consumo de ração $(\mathrm{P}<0,05) \mathrm{e}$ a conversão alimentar por massa $(\mathrm{P}<0,01)$ e por dúzia de ovos ( $\mathrm{P}<0,01)$, mas não afetaram $(\mathrm{P}>0,05)$ as demais características de desempenho avaliadas (Tabela 2). O consumo de ração pelas codornas foi influenciado $(\mathrm{P}<0,05)$ pela densidade energética das dietas e aumentou 8,9\% quando a densidade das dietas reduziu de 2.900 para $2.500 \mathrm{kcal}$ de $\mathrm{EM} / \mathrm{kg}$.

Este resultado corrobora os obtidos por Ângulo et al. (1993), que observaram aumento no consumo de ração em codornas japonesas no período de 0 a 33 dias de idade ao reduzirem o nível energético de 3.200 para 3.000 kcal de EM/kg de dieta. Murakami et al. (1993), Pinto et al. (2002) e Freitas et al. (2005) também verificaram aumento linear do consumo de ração com a redução do nível de energia para codornas japonesas. Desta forma, pode-se inferir que o comportamento alimentar de codornas é semelhante ao de galinhas poedeiras, que alteram o consumo de ração de acordo com o nível de energia da dieta (Murakami, 1993; Belo et al., 2000; Garcia et al., 2000; Pinto et al., 2002).

De acordo com Sakurai (1981) e Murakami (1993), para codornas também é possível aplicar a teoria quimiostática, ou seja, de que regulam seu consumo de acordo com a necessidade de energia, no entanto, outros fatores também podem influenciar o consumo, como a necessidade da ave, 
o peso corporal, a fase de postura, o crescimento, a mantença e o ambiente de criação (Albino \& Barreto, 2003).

Não foi observada diferença $(P>0,05)$ entre as dietas para o consumo diário de energia metabolizável. As aves mantiveram os valores absolutos próximos, que variam de 69,7 a 66,1 kcal de EM/ave/dia, o que indica que, como em outras espécies de aves, as codornas também se alimentam para satisfazer a exigência de energia. De acordo com Yamane et al. (1980) e o NRC (1994), o consumo diário de energia de codornas japonesas para máxima produção deve ser de 63 a 75 kcal/ave/dia. Freitas et al. (2005), avaliando vários níveis de EM para codornas japonesas, concluíram que houve ingestão média de $66 \mathrm{kcal} / \mathrm{ave} / \mathrm{dia}$.

O consumo de proteína bruta não diferiu $(\mathrm{P}>0,05)$ entre as aves. Uma vez que as codornas mantiveram praticamente a mesma ingestão de energia metabolizável e a correção do nível protéico em relação à energia da dieta, o consumo de proteína bruta também foi corrigido, o que contraria as observações de Belo et al. (2000) e Freitas et al. (2005), que encontraram maior consumo de PB pelas aves alimentadas com as dietas contendo 2.600 e $2.585 \mathrm{kcal}$ de EM/kg, respectivamente. Esse maior consumo é explicado pelo fato de as codornas se alimentarem para satisfazer a exigência de energia e aumentar a ingestão de proteína. Entretanto, se a relação EM:PB tivesse sido corrigida de acordo com os níveis energéticos da ração, provavelmente o consumo de proteínas pelas codornas teria sido maior.

Como houve correção nos níveis de proteína bruta e a inclusão de aminoácidos sintéticos para a adequação da relação energia metabolizável:aminoácidos nas dietas, o consumo de aminoácidos foi corrigido, ou seja, não foi afetado $(\mathrm{P}>0,05)$ pela densidade energética das dietas. Portanto, não houve diferença $(\mathrm{P}>0,05)$ nos consumos de lisina, metionina+cistina e treonina. Com o aumento do consumo da dieta, ocasionado pela redução da densidade energética, e com a semelhante relação energia metabolizável: aminoácidos entre as dietas, houve ajustamento na ingestão desses aminoácidos pelas aves.

Em trabalho realizado por Ribeiro et al. (2003), a estimativa da exigência de lisina para codornas foi 7 e 15\% maior que o nível recomendado pelo NRC (1994), considerando que as dietas continham 20 e $23 \%$ de PB, respectivamente, e 2.900 kcal de energia metabolizável. Esses dados sugerem que, semelhantemente ao ocorrido em outras espécies, a exigência quantitativa de lisina para codornas também aumenta com o nível de proteína bruta da ração (Morris et al., 1987; Rose \& Uddin, 1988). No entanto, outro fator que pode ter elevado a exigência deste aminoácido é a mudança na relação entre a EM e o nível de lisina na dieta, ou seja, houve melhoria no consumo de lisina.
A densidade energética das dietas não influenciou $(P>0,05)$ a produção de ovos, no entanto, em valores absolutos, as codornas alimentadas com a dieta que continha $2.500 \mathrm{kcal}$ de EM/kg apresentaram o pior desempenho e produziram 7,5 e 8,5\% menos ovos que as codornas alimentadas com a dieta de 2.800 e $2.900 \mathrm{kcal}$ de EM/kg, respectivamente. Apesar da diferença não-significativa $(\mathrm{P}>0,05)$, a presença de óleo de soja em maiores quantidades nas dietas mais energéticas provavelmente favoreceu os processos fisiológicos da digestão, o que deu suporte, em termos absolutos, para a produção de ovos. Provavelmente, o menor incremento calórico das dietas com 2.900 e 2.800 kcal de $\mathrm{EM} / \mathrm{kg}$ aumentou, mais que proporcionalmente, a energia líquida, elevando a produção de ovos.

Estudando a densidade energética sem manter a relação entre energia metabolizável e os nutrientes em dietas para codornas japonesas, Belo et al. (2000), Pinto et al. (2002) e Freitas et al. (2005) não encontraram diferenças ( $\mathrm{P}>0,05)$ na produção de ovos. Ao contrário, Yamane et al. (1980), Murakami et al. (1993) e Cordeiro et al. (2003) observaram aumento na produção de ovos com a redução da densidade energética e do nível protéico fixo. Djouvinov \& Mihailov (2005) avaliaram dietas com 18,2 e 16,7\% de proteína bruta, mantendo os níveis de energia e lisina, para codornas japonesas e observaram que o maior consumo da dieta com menor nível de proteína fez com que, mesmo assim, ocorresse maior ingestão de aminoácidos, o que acarretou maior produção e massa de ovos. Em todos esses trabalhos, não foi considerada a relação energia metabolizável: nutrientes, assim, as dietas com os níveis mais baixos de energia resultaram em melhor produção. Contudo, o aumento no consumo de ração piorou a conversão alimentar por massa e por dúzia, índices zootécnicos decisivos no sucesso de produção.

A produção de ovos comercializáveis não diferiu $(\mathrm{P}>0,05)$ entre as dietas. No entanto, em valores absolutos, as codornas alimentadas com a dieta de $2.500 \mathrm{kcal}$ de EM/kg produziram aproximadamente $15 \%$ menos ovos comercializáveis que aquelas alimentadas com as dietas de 2.900 e $2.800 \mathrm{kcal}$ de $\mathrm{EM} / \mathrm{kg}$.

Também não houve diferença $(\mathrm{P}>0,05)$ para peso e massa de ovo, logo, qualquer uma das dietas utilizadas no experimento foi eficiente para esta característica de desempenho. O consumo de lisina e dos outros nutrientes foi muito próximo entre as aves e deu sustentabilidade similar à formação do ovo. Perly (1979), Murakami \& Furlan (2002) e Pinto et al. (2002) mencionaram que o peso e a massa de ovo são influenciados pela ingestão diária de proteína em poedeiras. Para produção de ovos maiores, as codornas devem ingerir maior quantidade de proteína (Soares et al., 
Tabela 2 - Desempenho de codornas japonesas alimentadas com cinco diferentes dietas

\begin{tabular}{|c|c|c|c|c|c|c|}
\hline & \multicolumn{5}{|c|}{ Nível de energia metabolizável (kcal/kg) } & $\mathrm{CV}(\%)^{1}$ \\
\hline Consumo de ração (g/ave/dia) ${ }^{2}$ & $24,6 a$ & $25,2 \mathrm{ab}$ & $25,4 \mathrm{abc}$ & $26,7 \mathrm{bc}$ & $27,0 \mathrm{c}$ & 5,047 \\
\hline Consumo de PB (g/ave/dia) & 4,92 & 4,87 & 4,73 & 4,79 & 4,65 & 4,842 \\
\hline Consumo de lisina (mg/ave/dia) & 298,9 & 297,9 & 287,5 & 291,0 & 283,8 & 4,824 \\
\hline Consumo de lisina digestível (mg/ave/dia) & 274,8 & 271,2 & 264,4 & 267,1 & 258,2 & 4,816 \\
\hline Consumo de treonina (mg/ave/dia) & 205,4 & 201,6 & 197,6 & 199,2 & 192,5 & 4,836 \\
\hline Consumo de treonina digestível (mg/ave/dia) & 179,6 & 176,4 & 172,7 & 173,6 & 170,1 & 4,839 \\
\hline Produção (\%) & 93,9 & 92,9 & 88,4 & 89,1 & 85,9 & 6,950 \\
\hline Produção de ovos comercializáveis (\%) & 84,4 & 83,8 & 81,1 & 82,2 & 71,9 & 11,701 \\
\hline Peso do ovo (g) & 12,25 & 12,34 & 12,18 & 12,31 & 12,11 & 2,376 \\
\hline Massa de ovo (g/ave/dia) & 11,41 & 11,42 & 10,97 & 11,09 & 11,17 & 9,769 \\
\hline Ganho de peso (g) & 28,0 & 28,0 & 21,0 & 25,0 & 24,0 & 5,148 \\
\hline Viabilidade (\%) & 98,0 & 94,0 & 97,0 & 96,0 & 94,0 & 6,787 \\
\hline
\end{tabular}

${ }^{1} \mathrm{CV}(\%)$ - coeficiente de variação.

2 Diferença significativa $(P<0,05)$ pelo teste SNK

3 Diferença significativa $(P<0,01)$ pelo teste SNK.

2003). Freitas et al. (2005) observaram aumento médio de 0,001 g no peso do ovo para cada kcal de redução na energia da dieta e aumento linear de $7,2 \%$ na massa de ovo quando reduziram de 2.885 para $2.585 \mathrm{kcal}$ de EM/kg de dieta. Segundo os autores, esse efeito esteve relacionado ao maior consumo de ração à medida que se reduziu a EM, ocasionando, conseqüentemente, maior ingestão de aminoácidos. Stringhini et al. (1995), Belo et al. (2000) e Barreto et al. (2007) também verificaram efeito linear crescente da redução da densidade energética sobre o peso dos ovos.

Em virtude do maior consumo de ração pelas codornas com a redução da densidade energética da dieta, houve piora $(\mathrm{P}<0,01)$ na conversão alimentar por massa e por dúzia de ovos. As dietas com densidade de 2.900 e $2.800 \mathrm{kcal}$ de $\mathrm{EM} / \mathrm{kg}$ não diferiram estatisticamente e promoveram a melhor conversão alimentar por massa e por dúzia de ovos. O nível de $2.500 \mathrm{kcal}$ de EM/kg de dieta foi o que proporcionou a pior conversão alimentar, tanto para massa como para dúzia de ovos. Resultados próximos para melhor conversão alimentar por massa e por dúzia de ovos foram observados por Belo et al. (2000) nos níveis de 2.900 e 3.000 kcal de EM/kg. Pinto et al. (2002) obtiveram melhores valores para conversão alimentar nos níveis de 2.950 e 3.050 kcal de EM/kg de dieta. Outros resultados similares foram encontrados por Murakami et al. (1993) e Freitas et al. (2005), que verificaram piora da conversão alimentar por dúzia, e não por massa de ovos, com a redução dos níveis de energia de
3.000 para $2.500 \mathrm{kcal}$ de EM/kg e de 2.885 para $2.585 \mathrm{kcal}$ de $\mathrm{EM} / \mathrm{kg}$, respectivamente.

As eficiências energéticas por massa e por dúzia de ovos não foram influenciadas $(\mathrm{P}>0,05)$ pela densidade energética da dieta, resultados que comprovam que todas as dietas foram eficientes para a produção de ovos. Entretanto, deve-se considerar que houve influência não apenas da densidade energética, mas também da relação da EM e os outros nutrientes da dieta, que juntos promoveram consumo compensatório pelas aves.

O ganho de peso e a viabilidade das aves não diferiram $(\mathrm{P}>0,05)$ entre as dietas. Portanto, qualquer dieta foi eficiente para ganho de peso e manutenção da integridade das aves. Em trabalho com codornas japonesas, Pinto et al. (2002) também não observaram efeito da densidade energética sobre o ganho de peso.

\section{Conclusões}

Codornas japonesas regulam o consumo de ração de acordo com a densidade energética da dieta. No entanto, dietas contendo 2.900 e $2.800 \mathrm{kcal}$ de EM/kg, com mesma relação entre energia metabolizável e nutrientes, proporcionam melhor conversão alimentar por massa e por dúzia de ovos, respectivamente. Além disso, esses níveis melhoram, em termos absolutos, a produção de ovos. Portanto, a redução da densidade energética mantendo constante a relação energia metabolizável:nutrientes deve ser utilizada quando 
a finalidade é consumo, peso de ovo, ganho de peso e viabilidade para codornas japonesas em postura.

\section{Literatura Citada}

ALBINO, L.F.T.; BARRETO, S.L.T. Codornas: criação de codornas para produção de ovos e carne. Viçosa, MG: Aprenda Fácil, 2003. 289p.

ÂNGULO, E.; BRUFAL, J.; MIQUEL, A. et al. Research note: Effect of diet density and pelleting on productive parameters of Japanese quail. Poultry Science, v.72, p.607-610, 1993.

BARRETO, S.L.T.; PEREIRA, C.A.; UMIGI, R.T. et al. Determinação da exigência de cálcio de codornas japonesas na fase inicial do ciclo de produção. Revista Brasileira de Zootecnia, v.36, n.1, p.68-78, 2007.

BARRETO, S.L.T.; QUIRINO, B.J.S.; BRITO, C.O. et al. Níveis nutricionais de energia sobre o desempenho e qualidade de ovos de codornas européias na fase inicial de postura. Revista Brasileira de Zootecnia, v.36, n.1, p.86-93, 2007.

BELO, M.T.S.; COTTA, J.T.B.; OLIVEIRA, A.I.G. Níveis de energia metabolizável em rações de codornas japonesas (Coturnix coturnix japonica) na fase inicial de postura. Ciência Agrotécnica, v.24, n.3, p.782-793, 2000.

CHWALIBOG, A.; BALDWIN R.L. Systems to predict the energy and protein requirements of laying fowl. World's Poultry Science Journal, v.51, p.187-196, 1995.

CORDEIRO, M.D.; SOARES, R.T.R.N.; AVILA, R.P. Níveis de energia metabolizável para codornas japonesas (Coturnix coturnix japonica) na fase inicial de postura. In: REUNIÃO ANUAL DA SOCIEDADE BRASILEIRA DE ZOOTECNIA, 40., 2003, Santa Maria. Anais... Santa Maria: Sociedade Brasileira de Zootecnia, 2003. p.187-194.

DJOUVINOV, D.; MIHAILOV, R. Effect of low protein level on performance of growing and laying Japanese quails (Coturnix coturnix japonica). Bulgarian Journal of Veterinary Medicine, v.8, n.2, p.91-98, 2005.

FREITAS, A.C.; FUENTES, M.F.F.; FREITAS, E.R. et al. Efeito de níveis de proteína bruta e de energia metabolizável sobre o desempenho de codornas de postura. Revista Brasileira de Zootecnia, v.34, n.3, p.838-846, 2005.

GARCIA, E.R.M.; MURAKAMI, A.E.; GALLI, J.R. Efeito do nível energético e da densidade populacional sobre o desempenho de codornas (Coturnix coturnix japonica) em postura. Revista Brasileira de Ciência Avícola, v.2, p.47, 2000.

INSTITUTO NACIONAL DE LA RECHERCHÉ AGRONOMIQUE - INRA Alimentação dos animais monogástricos: suínos, coelhos e aves. 2.ed. São Paulo: Roca, 1999. 245p.

MORRIS, T.R.; AL-AZZAWI, K.; GOUS, R.M. Effects of protein concentration on responses to dietary lysine by chicks. British Poultry Science, v.28, p.185-195, 1987.

MURAKAMI, A.E.; MORAES, V.M.B.; ARIKI, J. Níveis de proteína e energia em dietas de codornas japonesas (Coturnix coturnix japonica) em postura. Revista Brasileira de Zootecnia, v.22, n.4, p.541-551, 1993.

MURAKAMI, A.E.; FURLAN, A.C. Pesquisa na nutrição e alimentação de codornas em postura no Brasil. In: SIMPÓSIO INTERNACIONAL DE COTURNICULTURA, 2002, Lavras. Anais... Lavras: Universidade Federal de Lavras, 2002. p.113-120.

NATIONAL RESEARCH COUNCIL - NRC. Nutrient requirements of poultry. 9.ed. Washington, D.C.: National Academy of Sciences, 1994. 155p.

PERLY, L. Correlação entre índice morfológico, peso do ovo e peso vivo ao final da fase de crescimento em codornas domésticas (Coturnix coturnix coturnix). Revista do Setor de Ciências Agrárias, v.1, n.1, p.41-53, 1979.

PINTO, R.; FERREIRA, A.S.; ALBINO, L.F.T. et al. Níveis de proteína e energia para codornas japonesas em postura. Revista Brasileira de Zootecnia, v.32, n.5, p.1761-1770, 2002.

PINTO, R.; FERREIRA, A.S.; DONZELE, J.L. et al. Exigência de lisina para codornas japonesas em postura. Revista Brasileira de Zootecnia, v.32, n.5, p.1182-1189, 2003.

RIBEIRO, M.L.G.; SILVA, J.H.V.; DANTAS, M.O. et al. Exigências nutricionais de lisina para codornas durante a fase de postura, em função do nível de proteína da ração. Revista Brasileira de Zootecnia, v.32, n.1, p.156-161, 2003.

ROSE, S.P.; UDDIN, M.S. Effect of temperature on the response of broiler chickens to dietary lysine balance. British Poultry Science, v.39, p.36-37, 1988.

SAKURAI, H. Influence of dietary levels of protein and energy balance for egg production of Japanese quail. Japanese Poultry Science, v.18, n.3, p.185-190, 1981.

SILVA, J.H.V.; SILVA, M.B.; SILVA, E.L. et al. Energia metabolizável de ingredientes determinada com codornas japonesas (Coturnix coturnix japonica). Revista Brasileira de Zootecnia, v.32, n.6, p.1912-1918, 2003.

SOARES, R.T.R.N.; FONSECA, J.B.; SANTOS, A.S.O. et al. Protein requeriment of japanese quail (Coturnix coturnix japonica) during rearing and laying periods. Revista Brasileira de Ciência Avícola, v.5, n.2, 2003.

STRINGHINI, J.H.; CAFÉ, M.B.; MOGYCA, N.S. et al. Níveis de energia metabolizável e metionina para codornas japonesas em postura (Coturnix coturnix coturnix). In: CONFERÊNCIA APINCO DE CIÊNCIA E TECNOLOGIA AVÍCOLAS, Curitiba, 1995, Anais... Campinas: Fundação Apinco de Ciência e Tecnologia Avícolas, 1995. p.125-126.

UMIGI, R.T.; BARRETO, S.L.T.; DONZELE, J.L. et al. Níveis de treonina digestível em dietas para codorna japonesa em postura. Revista Brasileira de Zootecnia, v.36, n.6, p.1868-1874, 2007.

UNIVERSIDADE FEDERAL DE VIÇOSA - UFV. Sistema de análises estatísticas e genéticas - SAEG. Versão 8.0. Viçosa, MG, 2000. 142p.

YAMANE, T.; ONO, K.; TANAKA, T. Energy requerimentof laying Japanese quail. British Poultry Science, v.21, p.451-455, 1980. 